\title{
Early Effect of Epidural Analgesia on Fetal Acid-base Balance in the First Stage of Labour
}

Raquel Garcia Delgado ${ }^{1 *}$, Octavio Ramirez Garcia ${ }^{1}$, Eva E Alvarez Leon ${ }^{2}$, Raquel Garcia Rodriguez ${ }^{1}$, Luciana Obreros Zegarra ${ }^{1}$ and Jose A Garcia Hernandez ${ }^{1}$ ${ }^{1}$ Department of Obstetrics and Gynecology, Hospital Universitario Materno Infantil de Canarias, Las Palmas de Gran Canaria, Spain

${ }^{2}$ Department of Preventive Medicine, Hospital Universitario Insular de Canarias, Las Palmas de Gran Canaria, Spain

"Corresponding author: Raquel Garcia Delgado, Department of Obstetrics and Gynecology, Hospital Universitario Materno Infantil de Canarias, Las Palmas de Gran Canaria, Spain, E-mail: rgdelgado1@hotmail.com

Received date: November 01, 2018; Accepted date: November 21, 2018; Published date: November 26, 2018

Copyright: $\odot 2018$ Delgado RG, et al. This is an open-access article distributed under the terms of the Creative Commons Attribution License, which permits unrestricted use, distribution, and reproduction in any medium, provided the original author and source are credited.

\begin{abstract}
Introduction: Epidural analgesia is a consolidated therapeutic technique generally used for the relief of labor pain. Since its introduction in obstetrics, there have been many studies that evaluate the effect that this type of analgesia has over the course of labor, and its possible repercussions on the mother and the fetus/newborn by analyzing data at birth. However, there exist very few studies that analyze the early effect that epidural analgesia has on the fetus.
\end{abstract}

Objectives: The main objective of this study is to analyze the early effects of epidural analgesia on the fetal status by evaluating the possible changes in the acid-base fetal state, the most precise way to evaluate fetal wellbeing during labor, and cardiotocographic (CTG) tracing of the fetal heart rate after the administration of an epidural.

Methods: This is a prospective study of 193 patients, in which a determination of the fetal acid-base equilibrium was done before the administration of epidural analgesia and repeated 60 min afterwards, evaluating possible changes in the results motivated by analgesia.

Results: There was a statistically significant descent on fetal blood $\mathrm{pH}$ after the administration of epidural analgesia, as well as a significant increase in the number of fetal heart traces with alterations. The descent of fetal $\mathrm{pH}$ was greater in patients that had some gestational associated conditions.

Conclusion: The administration of epidural analgesia during the first stage of labor caused, as an early effect, a significant descent in fetal blood $\mathrm{pH}$, without that descent being clinically relevant over the fetal status in healthy fetuses. There must be a strict control in fetuses with some initial alteration in the CTG tracings.

Keywords Acid-base balance; Epidural; Early effect of epidural in fetus; Fetal blood $\mathrm{pH}$

\section{Introduction}

Epidural analgesia is a consolidated therapeutic technique generally used for pain relief during labor. Nowadays the analgesic superiority of this technique is unquestionable; however, it is not exempt from side effects and complications. The use of local anesthetics in the epidural space can be associated with changes in fetal heart rate patterns due to maternal hypotension, that it sometimes causes, and possible direct effects on the fetus [1-3].

Since its introduction in obstetrics to date, there have been multiple studies whose objective was to determine effects caused by epidural analgesia over the course of labor and its potential impact on the mother and fetus/neonate. Despite the large amount of information on the literature on the effects of this type of analgesia on fetal status, there are few studies that analyze the early effect of epidural analgesia; since most base their conclusions on data obtained after completion of the birth process.
Fetal blood analysis was the first method that allowed the direct study of the

live fetus. This method has great significance in intrapartum fetal monitoring since to establish acid-base status of fetus is the most accurate way to assess fetal well-being during labor. Currently, biochemical monitoring is the ideal complement of biophysical monitoring, because it reduces its high rate of false positives and determines the existence of risk for fetal distress in an absolute way, due to its complete reliability of data on its mechanism and severity [4-7]. It is, therefore, the gold standard technique with which all others are compared [8].

The main objective of this study is to analyze the early effects of epidural analgesia on fetal status, evaluating possible changes in fetal acid-base status and in the CTG fetal heart rate tracings after administration of epidural analgesia.

The secondary objectives are the analysis of the early effect of epidural analgesia on the fetus according to maternal pathology and the analysis of long-term effects of epidural analgesia assessing the status of the newborn. 


\section{Materials and Methods}

During a period of 3 and a half years, the results of the acid-base status and fetal heart rate of 193 expectant women was obtained prior to administration of epidural analgesia and $60 \mathrm{~min}$ after its administration, evaluating possible changes motivated by analgesia.

All the patients were pregnant women who were admitted to the Delivery Room area of our center.

All pregnant women received epidural analgesia during the first stage of labor and fulfilled the study inclusion criteria: Fetus in longitudinal situation and cephalic presentation, ruptured membranes allowing the realization of a fetal capillary microtome, minimal dilation degree that allowed the realization of fetal capillary microtome, not contraindications for fetal study (known or suspected fetal blood dyscrasias, face or brow presentation, maternal human immunodeficiency virus or positive status or active maternal genital infection like herpes simplex virus, hepatitis B or C), absence of contraindications for the administration of epidural analgesia, no administration of epidural analgesia before inclusion in the study, no delivery forecast before $1 \mathrm{~h}$ time. As well as the patient's voluntary acceptance of their inclusion in the study after receiving appropriate and sufficient verbal information, and their subsequent signature on the informed consent form. The study was approved by the Hospital ethics committee (CEIC-CHUIMI-2015/795).

A total of 214 patients were initially included in the study, from which 21 had to be excluded for several reasons: The expulsive period arose in 17 patients prior to the administration of epidural analgesia, it was not possible to perform fetal blood microtome in one patient due to technical difficulties and cervical dilation got very advanced in two patients when the fetal capillary sample was to be performed so that its realization was dismissed. A total of 30 patients met the inclusion criteria but refused to participate. Most of them because they presented severe pain and didn't want to delay the administration of epidural analgesia. These patients did not differ from those included in the study in terms of their demographic characteristics and levels of gestational risk factors.

For the extraction of the fetal scalp blood sample a disposable kit (Fetal blood sampling kit ref Reorder 4520AA0 GE Medical Systems Information Technologies) was used.

After the taking of blood for determining the fetal acid-base balance, epidural analgesia was administered according to the usual technique with $50 \mu \mathrm{g}$ administration of fentanyl and bupivacaine $0.25 \%$. Continuous infusion was initiated after the initial bolus analgesic effects were observed; rate was $10-12 \mathrm{ml} / \mathrm{h}$. Repeat boluses were administered in the case that continuous infusion was insufficient to achieve adequate analgesia. Monitoring fetal heart rate was performed internally and continuously through the placement of a fetal scalp electrode. The pattern of fetal heart rate was analyzed prior to administration of epidural analgesia and afterwards. The fetal heart rate was grouped into four categories to facilitate interpretation (Table 1): normal, with transient impairment, pre-pathological and pathological.

\begin{tabular}{|l|l|l|l|l|}
\hline & Baseline rate & Variability (bpm) & Accelerations & Decelerations \\
\hline Normal & $110-160$ & 5 bpm or more & Present & None \\
\hline Transient impairment & Isolated alteration corrected in a short period of time & $\begin{array}{l}\text { Early decelerations or single variable or } \\
\text { deceleration up to } 3 \text { min }\end{array}$ \\
\hline Pre-pathological & $100-109$ & $<5$ for 40 min-90 min & None & $\begin{array}{l}\text { Repeated variables or late decelerations or } \\
\text { prolonged decelerations more than } 3 \text { min }\end{array}$ \\
\hline Pathological & $<100$ or $>160$ & $<5$ for 90 min or more & None & \\
\hline Bpm: Beats per minute & & & \\
\hline
\end{tabular}

Table 1: Classification of fetal heart rate.

During the dilation period the normal limits of $\mathrm{pH}$ are 7.45 to 7.25 , and during the expulsive period from 7.45 to 7.20 ; acidosis is considered below these values (Committee on Technical Bulletins of the American College of Obstetricians and Gynecologist, 1989) [9].

- A pH $\geq 7.25$ is considered normal.

- A pH between 7.24 and 7.20 is of dubious value and is recommended to repeat the analysis after 20-30 $\mathrm{min}$.

- When the $\mathrm{pH}$ is $<7.20$ it is considered a pathological value. There is risk of loss fetal well-being [10]. The fetus should be extracted immediately by the quickest route.

Statistical analysis of the variables was performed using the SPSSPC statistical program version 23.0.

Categorical variables are expressed as percentages. The Chi-squared test was used to evaluate differences between variables. Fisher's exact test is indicated when the Chi-square test is not applicable because of having to handle very small sample sizes. Continuous variables are expressed as average and standard deviation. The differences between these variables are assessed by using the t-Student test for normally distributed variables or the nonparametric Mann-Whitney test for non-normal ones. A continuous variable analysis of variance (ANOVA) was used to compare more than two means. The Bonferroni procedure was used to make all possible pairwise comparisons of means (or multiple comparisons post-hoc procedures).

The level of statistical significance was set to a value of $\mathrm{p}<0.05$.

\section{Results}

The study included patients with low and high risk pregnancies. The baseline characteristics of the study population are shown in Table 2. 
Citation: Delgado RG, Garcia RO, Leon EEA, Rodriguez RG, Zegarra LO, et al. (2018) Early Effect of Epidural Analgesia on Fetal Acid-base Balance in the First Stage of Labour. Clinics Mother Child Health 15: 308. doi:10.4172/2090-7214.1000308

Page 3 of 6

\begin{tabular}{|c|c|c|c|c|c|}
\hline Demographics & \multicolumn{2}{|c|}{ Mean value } & Standard Deviation (DS) & \multicolumn{2}{|c|}{ Range } \\
\hline Age & \multicolumn{2}{|c|}{29.08 years } & 5.7 & \multicolumn{2}{|c|}{$16-41$ years } \\
\hline Parity & \multicolumn{2}{|c|}{1.74 births } & 0.9 & \multicolumn{2}{|c|}{ 1-6 births } \\
\hline Weight & \multicolumn{2}{|c|}{$78.32 \mathrm{Kg}$} & 13.5 & \multicolumn{2}{|c|}{$47-124 \mathrm{Kg}$} \\
\hline Height & \multicolumn{2}{|c|}{$162.19 \mathrm{~cm}$} & 6.4 & \multicolumn{2}{|c|}{$148-180 \mathrm{~cm}$} \\
\hline BMI & \multicolumn{2}{|c|}{29.77 kg/cm2 } & 4.9 & \multicolumn{2}{|c|}{$18.7-47.5 \mathrm{~kg} / \mathrm{cm} 2$} \\
\hline \multicolumn{6}{|l|}{ Associated conditions } \\
\hline \multicolumn{3}{|l|}{ Medical conditions } & \multicolumn{3}{|l|}{ Gestational conditions } \\
\hline & $\mathbf{N}$ & $\%$ & & $\mathbf{N}$ & $\%$ \\
\hline Asthma & 12 & 6.21 & Preterm labour & 1 & 0.51 \\
\hline Pregestational diabetes & 1 & 0.51 & Mild Anemia & 1 & 0.51 \\
\hline Crohn's disease & 1 & 0.51 & IUGR & 5 & 2.59 \\
\hline Hypothyiroidism & 4 & 2.07 & Gestational diabetes & 9 & 4.66 \\
\hline Chronic HBP with treatment & 8 & 4.14 & Sterility & 1 & 0.51 \\
\hline \multirow[t]{9}{*}{ Chronic HBP without treatment } & \multirow[t]{9}{*}{1} & \multirow[t]{9}{*}{0.51} & Polyhydramnios & 2 & 1.03 \\
\hline & & & Gestational hypertension & 7 & 3.62 \\
\hline & & & Pneumonia & 2 & 1.03 \\
\hline & & & Oligohydramnios & 10 & 5.18 \\
\hline & & & SGA & 4 & 2.07 \\
\hline & & & Pyelonephritis & 2 & 1.03 \\
\hline & & & Placenta previa (marginal) & 1 & 0.51 \\
\hline & & & Preeclampsia & 8 & 4.14 \\
\hline & & & DVT & 1 & 0.51 \\
\hline
\end{tabular}

Table 2: Study population characteristics.

The average $\mathrm{pH}$ of fetal blood microtomes made prior to the administration of epidural analgesia (pre-epidural $\mathrm{pH}$ ) is 7.35 (SD 0.042). The pre-epidural $\mathrm{pH}$ range is 7.25-7.45. They are, therefore, all values that indicate normal and fetal wellbeing.

The average $\mathrm{pH}$ of fetal blood microtome performed at $60 \mathrm{~min}$ after administration of epidural analgesia is 7.32 (SD 0.03 and range from 7.18 to 7.43$)$.
By a comparative analysis between the result of fetal acid-base balance obtained prior to administration of epidural analgesia and after its administration (pre and post-epidural $\mathrm{pH}$, respectively) there is a statistically significant $(\mathrm{p}<0.001)$ decrease in fetal $\mathrm{pH}$ after epidural analgesia (Table 3 and Figure 1).

\begin{tabular}{|l|l|l|l|l|}
\hline & $\mathbf{n}$ & Mean $\mathbf{p H}$ & Standard deviation & \\
\hline Pre-epidural $\mathrm{pH}$ & 193 & 7.3497 & 0.04223 & $\mathrm{P}<0.001$ \\
\cline { 1 - 3 } & 193 & 7.3212 & 0.03931 & \\
\hline
\end{tabular}

Table 3: Difference between pre and post-epidural $\mathrm{pH}$ in the study population. 


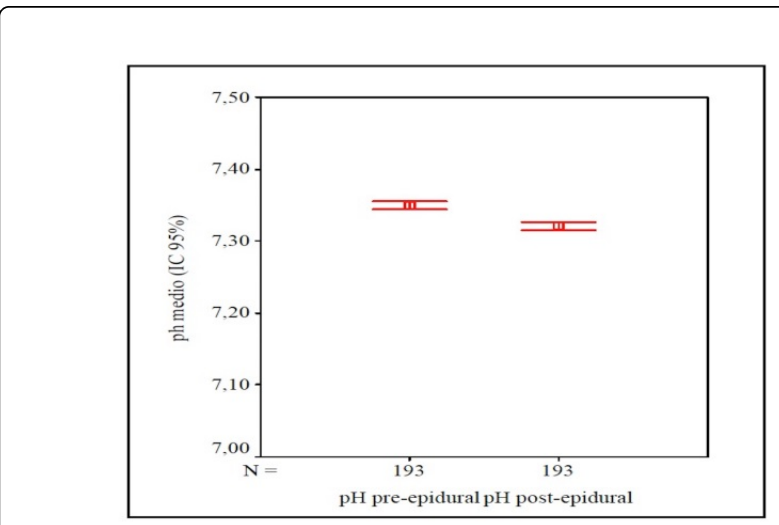

Figure 1: Pre and post-epidural $\mathrm{pH}$ in the study population.

The $\mathrm{pH}$ performed after administration of epidural analgesia decreased an average of 0.03 units (SD 0.05), with a confidence interval of $95 \%$ for the average difference of 0.02 to 0.04 .

A small number of patients experienced side effects to epidural analgesia. The most common side effect was incomplete analgesia (7.8\% of the study population). In a patient with incomplete analgesia a new epidural analgesia was administered and did prove effective in pain relief. $4.7 \%$ of patients had post-epidural hypotension which was successfully treated in all cases (hydration or/with intravenously ephedrine). All patients had recovered hypotension when the second fetal acid-base balance was performed. There was no difference in the $\mathrm{pH}$ decrease in this group of patients. After administration of epidural analgesia, there was no pregnant woman with hypotension as a side effect from epidural analgesia who had pathological or pre-pathologic fetal blood $\mathrm{pH}$.

$87.6 \%$ of patients had adequate uterine contractions after administration of epidural analgesia. This percentage is higher than the one before administration of analgesia (77.7\% with normal uterine contractions, without hypo-or hyperdynamic).

Fetal heart rate tracing prior to the administration of epidural analgesia was normal in $96.9 \%$. The percentage of patients with an abnormality of the fetal heart rate increased significantly compared to the previous period: from $3.1 \%$ to $12.4 \%(\mathrm{p}<0.05)$.

If we analyze results independently by taking into consideration the patients according to their gestational pathology, we conclude that administration of epidural analgesia during the first period of labor caused a greater decrease in fetal blood $\mathrm{pH}$ in patients with a gestational pathology, with an increased percentage of postepidural pathological fetal blood $\mathrm{pH}$ values in patients with diabetes and/or gestational hypertension. The postepidural $\mathrm{pH}$ in patients with gestational diabetes was lower than in patients without it, with statistically significant difference $(\mathrm{p}<0.05)$.

The administration of epidural analgesia during the first period of labor did not cause a decrease in fetal blood $\mathrm{pH}$ in pregnant women with preeclampsia and those with fetuses with IUGR, a situation which differentiates it from the rest of the patients, but did not reach significance statistical probably due to the small number of patients with this pathology.

A positive correlation between pre-and postepidural $\mathrm{pH}$ values and Apgar score was observed; there was a statistically significant positive correlation $(\mathrm{p}<0.05)$ between the preepidural $\mathrm{pH}$ and the value of Apgar score at $1 \mathrm{~min}$ and $5 \mathrm{~min}$.

The greater the decrease in fetal capillary $\mathrm{pH}$ value, the lower Apgar score at one minute and five minutes after birth. This negative correlation is statistically significant for the first minute Apgar $(\mathrm{p}<0.05)$.

Newborns with an arterial cord $\mathrm{pH}$ under 7 had a lower pre and post-epidural $\mathrm{pH}$ than newborns with normal arterial cord $\mathrm{pH}$ values, without reaching statistical significance.

\section{Discussion}

We found a decrease in fetal blood $\mathrm{pH}$ after epidural analgesia but despite it being a statistically significant decrease, the impact in clinical practice is minimal, since such variation in fetal blood $\mathrm{pH}$ does not alter the management of the pregnancy nor has consequences on fetal well-being. This is because, although the $\mathrm{pH}$ descended, the capillary $\mathrm{pH}$ value in most cases remained above 7.25. A fetus with a capillary $\mathrm{pH}$ above 7.25 is a fetus that does not have acidosis, and therefore, there is no clinical impact in most of the study cases.

Between the 60s and 80s, there have been lots of studies that show that labor itself does not cause a decrease in fetal capillary $\mathrm{pH}$ throughout the whole dilation period [11-19]. A decrease in fetal capillary $\mathrm{pH}$ has been described during the second stage of labor (expulsive period).

A more recent study by Nikolov, et al. [20], analyzes the reference values of fetal oxygenation during the first and second stage of labor. It was used a fetal pulse oximeter in 94 pregnancies with standard intrapartum CTG trace. A statistically significant difference $(\mathrm{p}<0.05)$ between the values of the first and second stage of labor was observed.

Several studies evaluating the early effect of epidural analgesia have been published; however, none of them make use of fetal capillary $\mathrm{pH}$.

East and Colditz [21] published a retrospective observational study that analyzed the differences in fetal oxygen saturation during the administration of the initial and of the maximum dose of epidural analgesia. They also analyzed the fetal oxygen saturation after administering additional doses of analgesia by infusion of boluses through the epidural catheter.

They conclude that fetal oxygenation is affected with the initial administration and maximum dose of epidural analgesia, regardless of maternal position and fetal electronic monitoring. In the presence of a stable maternal blood pressure, fetal oxygen saturation is not affected by the epidural bolus infusion. This study obtained similar results to those of our study, however, the case number is smaller and the method for assessing fetal welfare state is less accurate than the one we used in our study.

There are several studies published in the literature with a similar design but with a smaller number of cases and, therefore, a major limitation when drawing conclusions [22-26].

Another method of intrapartum fetal monitoring is the assessment of the fetal electrocardiogram. Phillips, et al. [27], published a study which measured the effect of epidural analgesia on fetal electrocardiographic tracing. They found that analgesia with bupivacaine does not affect fetal myocardial conduction and does not induce myocardial ischemic changes. A more recent study published by Becker, et al. [28,] evaluated the influence of intrapartum epidural 
analgesia on the occurrence of ST events of the fetal ECG. They carried out a case-control study in 144 pregnant women and did not find differences in the numbers or types of ST events in the two populations.

The effect of epidural analgesia on the fetus has also been analyzed by using Doppler study in the fetus and in the uterine arteries. In a prospective study, Valentin, et al. [29] analyzed the changes in Doppler velocimetry values in uterine artery, umbilical and fetal middle cerebral artery (MCA) after epidural analgesia in 12 pregnant women. This study demonstrated that, during labor, epidural analgesia with ropivacaine induced a significant decrease in uterine artery blood flow velocities, without any modification on the umbilical artery or the fetal MCA blood in a low-risk pregnancy. Chen, et al. [30] performed a similar study in 15 pregnant women. The results of this study indicated that although the S/D ratio, PI, and RI of the uterine artery were increased during long-term continuous epidural infusion for labor analgesia, these indices of the fetal umbilical and MCAs were not changed, suggesting that continuous epidural labor analgesia did not interfere with fetal circulation regardless of uterine contraction or relaxation.

There are lots of studies in which the effects of epidural in labor and long term fetal status are analyzed [31-36]. Most of them conclude that there are similar perinatal outcomes in patients undergoing epidural analgesia during labor and those without epidural analgesia. The last revision of the Cochrane Foundation [37] concluded that epidural analgesia did not appear to have any immediate effect on neonatal status as determined by Apgar scores or in admissions to neonatal intensive care. However, there are some studies that drew a different conclusion. Herrera-Gómez, et al. [38] performed a retrospective study in 2399 children. They concluded that Apgar index values at one minute and five minutes were significantly lower in neonates whose mothers had received epidural analgesia. Neonatal intensive care unit admission was also significantly more frequent in the epidural versus non-epidural group and resuscitation was significantly more frequent in the epidural group. On the other hand, Kumar, et al. [39] suggested in their case-control study that late-preterm and term infants exposed to maternal epidural analgesia in labour were more likely to develop respiratory distress in the immediate neonatal period.

Interestingly, pregnant women who have had preeclampsia and those with IUGR fetuses have an increase in fetal blood $\mathrm{pH}$ after epidural analgesia. This observed difference was not statistically significant in our study, probably due to the small number of patients with these diseases in our sample.

It is a known fact that in preeclampsia the uteroplacental vessels have a high resistance and blood flow reduction. The sympathetic blockade provoked by epidural analgesia causes vasodilation in the lower half of the body that may increase placental perfusion in women with preeclampsia, if perfusion pressure is maintained. There have been several studies in which the effect of epidural analgesia was analyzed in patients with preeclampsia and IUGR and are in agreement with the results obtained in our study [40-44].

\section{Conclusion}

The results of our study show that epidural analgesia produces no relevant clinical early effects on fetal state. In our study, the administration of epidural analgesia during the first period of labor caused a significant decrease in fetal blood $\mathrm{pH}$ without clinical repercussion in healthy fetuses as an early effect. However, after its administration, there was a significant increase in the number of tracings with impaired fetal heart rate. Pregnant women with some alteration in the CTG tracings showed a greater decrease in fetal blood $\mathrm{pH}$ after administration of epidural analgesia during the first period of labor.

Although the routine use of epidural analgesia seems to be safe in healthy fetuses, a strict control in the cases with some initial alteration in the CTG tracings is mandatory.

Further investigations with larger sample size should be performed in order to confirm these findings.

\section{Acknowledgments}

We are grateful to all the people who worked in the Delivery Room area of the Hospital Universitario Materno Infantil de Canarias "Maternal and Children University Hospital of Canarias, Las Palmas de Gran Canaria", for their assistance with the data collection.

\section{Funding}

There was no funding support for this study.

\section{Disclosure Statement}

The authors report no conflicts of interest.

\section{References}

1. Umstad MP, Ross A, Rushford DD, Permezel M (1993) Epidural analgesia and fetal heart rate abnormalities. Aust $N$ Z J Obstet Gynaecol 33: 269-272.

2. Al-Mufti R, Morey R, Shennan A, Morgan B (1997) Blood presure and fetal heart rate changes with patient-controlled combined spinal epidural analgesia while ambulating in labour. Br J Obstet Gynaecol 104: 554-558.

3. Palmer CM, Maciulla JE, Cork RC, Nogami WM, Gossler K, et al. (1999) The incidence of fetal heart rate changes after intrathecal fentanyl labor analgesia. Anesth Analg 88: 577-581.

4. Saling E (1971) Microanálisis sanguíneos en el feto. In: Saling E, (Ed) El niño desde el punto de vista obstétrico. Barcelona: Editorial CientíficoMédica 103-155.

5. Cabero Ll (1996) Sufrimiento fetal intraparto. Diagnóstico y tratamiento. In: Cabero Ll, (Ed.) Riesgo elevado obstétrico. Barcelona: Masson SA 481-535.

6. González A, Ezcurdia M (1996) Monitorización bioquímica fetal durante el parto. In: Fabre E, (Ed.) Manual de asistencia al parto y puerperio normal. Zaragoza: INO Reproducciones 333-346.

7. Carbonne B, Pons K, Maisonneuve E (2016) Foetal scalp blood sampling during labour for $\mathrm{pH}$ and lactates. Best Pract Res Clin Obstet Gynaecol 30: 62-67.

8. Martin R, McColgin SG (1990) Evaluation of fetal and neonatal acid-base status. Obstet Gynecol Clin North Am 17: 223-233.

9. Committee on Technical Bulletins of the American College of Obstetricians and Gynecologist (1989) Assessment of fetal and newborn acid-base status. Washington (DC), ACOG Technical Bulletin 127: 1-4.

10. Saling E (1981) Fetal scalp blood análisis. J Perinatol Med 9: 165-177.

11. Saling E (1963) Ztschr Geburtsh u. Gynäk 161: 262.

12. Beard RW, Morris ED (1965) Foetal and maternal acid-base balance during normal labour. J Obstet Gynaecol Br Commonw 72: 496-506.

13. Bowe E (1965) The assessment of fetal acid base status during labor. Bull Sloane Hosp 13: 6.

14. Fischer WM (1965) Investigation of acid-base equilibrium in fetal blood before birth. Arch Gynäk 200: 534-551. 
Citation: Delgado RG, Garcia RO, Leon EEA, Rodriguez RG, Zegarra LO, et al. (2018) Early Effect of Epidural Analgesia on Fetal Acid-base Balance in the First Stage of Labour. Clinics Mother Child Health 15: 308. doi:10.4172/2090-7214.1000308

Page 6 of 6

15. Kubli F, Berg D (1965) The early diagnosis of foetal distress. J Obstet Gynaec Brit Comm 72: 507-512.

16. Bretscher J, Saling E (1967) pH values en fetus during labor. Am J Obst and Gynec 97: 906-911.

17. Tatelbaum RC, Rosen MG (1968) Applicability and acceptability of fetal scalp blood sampling technic. Obstet Gynecol 32: 290-292.

18. Lumley J, McKinnon L, Wood C (1971) Lack of agreement on normal values for fetal scalp blood. J Obstet Gynaecol British Commonwealth 78: 13-21.

19. Ingermarsson I, Arulkumaran S (1986) Fetal acid-base balance in lowrisk patients in labor. Am J Obstet Gynecol 155: 66-69.

20. Nikolov A, Dimitrov A, Vakrilova L, Iarŭkova N, Tsankova M, et al. (2005) Reference values range of the fetal oxygen saturation and its dispersal during labor without cardiotocographic evidence for fetal distress. Akush Ginecol 44: 24-31.

21. East CE, Colditz PB (2002) Effect of maternal epidural analgesia on fetal intrapartum oxigen saturation. American J Perinatol 19: 119-126.

22. Valdelamar M, Siker D, Merlano M, Borre O, Pérez D (1994) Monitoreo contínuo de la saturación fetal de oxígeno: analgesia obstétrica vs dolor. Rev Col Anest 22: 109.

23. Johnson N, Van Oudgaarden E, Montague IA, McNamara H (1996) The effect of maternal epidural analgesia on fetal oxygen saturation. Br J Obstet Gynaecol 103: 776-778.

24. Kaita TM, Nikkola EM, Rantala MI, Ekblad UU, Salonen MA (2000) Fetal oxygen saturation during epidural and paracervical analgesia. Acta Obstet Gynecol Scand 79: 336-340.

25. Gao YF, Yu YH, Shi YS, Huang XL, Liu GW (2005) Effects of ambulatory labor analgesia on fetal oxygen saturation. Di Yi Jun Yi Da Xue Xue Bao 25: 1507-1510.

26. Carvalho B, Fuller AJ, Brummel C, Durbin M, Riley ET (2007) Fetal oxygen saturation after combined spinal-epidural labor analgesia: a case series. J Clin Anesth 19: 476-478.

27. Phillips K, Umstad MP, Donnelly JG, Cameron AD, Murphy KW (1996) The effect of epidural bupivacaine on the fetal electrocardiogram. Aust N Z J Obstet Gynaecol 36: 272-274.

28. Becker JH, Schaap TP, Westerhuis ME, Van Wolfswinkel L, Visser GH, et al. (2011) Intrapartum epidural analgesia and ST analysis of the fetal electrocardiogram. Acta Obstet Gynecol Scand 90: 1364-1370.

29. Valentin M, Ducarme G, Ceccaldi PF, Bougeouis B, Luton D (2012) Uterine artery, umbilical, and fetal cerebral Doppler velocities after epidural analgesia during labor. Int J Gynaecol Obstet 118: 145-148.

30. Chen LK, Yang YM, Yang YH, Lee CN, Chen SS, et al. (2011) Doppler measurement of the changes of fetal umbilical and middle cerebral artery velocimetric indices during continuus epidural labor analgesia. Reg Anesth Pain Med 36: 249-255.
31. Morgan-Ortiz F, Quintero-Ledezma JC, Pérez-Sotelo JA, Trapero-Morales M (1999) Evolution and quality of care during labor and delivery in primiparous patients who underwent early obstetrical analgesia. Ginecol Obstet Mex. 1999;67: 522-526.

32. Dickinson JE, Paech MJ, McDonald SJ, Evans SF (2002) The impact of intrapartum analgesia on labour ad delivery outcomes in nulliparous women. Aust N Z J Obstet Gynaecol 42: 59-66.

33. Soncini E, Grignaffini A, Anfuso S, Cavicchioni O (2003) Epidural analgesia during labour: maternal, fetal and neonatal aspects. Minerva Ginecol 55: 263-269.

34. Sienko J, Czajkowski K, Swiatek-Zdzienicka M, Krawczyńska-Wichrzycka R (2005) Epidural analgesia and the course of delivery in term primiparas. Ginekol Pol 76: 806-811.

35. Anim-Somuah M, Smyth R, Howell C (2011) Epidural versus nonepidural or no analgesia in labour. Cochrane Database Syst Rev 7: CD000331.

36. Wang Q, Zheng SX, Ni YF, Lu YY, Zhang B, et al. (2018) The effect of labor epidural analgesia on maternal-fetal outcomes: a retrospective cohort study. Arch Gynecol Obstet 298: 89-96.

37. Anim-Somuah M, Smyth R, Howell C (2018) Epidural versus nonepidural or no analgesia for pain management in labour. Cochrane Database Syst Rev 25: CD000331

38. Herrera-Gómez A, García-Martínez O, Ramos-Torrecillas J, De LunaBertos E, Ruiz C, et al. (2015) Retrospective study of the association between epidural analgesia during labour and complications for the newborn. Midwifery 31: 613-616.

39. Kumar M, Chandra S, Ijaz Z, Senthilselvan A (2014) Epidural analgesia in labour and neonatal respiratory distress: a case-control study. Arch Dis Child Fetal Neonatal Ed 99: F116-119.

40. Jouppila P, Jouppila R, Hollmén A, Koivula A (1982) Lumbar epidural analgesia to improve intervillous blood flow during labour in severe preeclampsia. Obstet Gynecol 59: 158-161.

41. Ramos-Santos E, Devoe LD, Wakefield ML, Sherline DM, Metheny W (1991) The effects of epidural anesthesia on the doppler velocimetry of umbilical and uterine arteries in normal and hypertensive patients during active term labor. Obstet Gynecol 77: 20-25.

42. Kanayama N, Belayet HM, Khatun S, Tokunaga N, Sugimura M, Kobayashi T, et al. (1999) A new treatment of severe pre-eclampsia by long-term epidural anaesthesia. J Hum Hypertens 13: 167-171.

43. Strümper D, Louwen F, Duriex ME, Gramke HF, Stuessel J, et al. (2005) Epidural local anesthetics: a ovel treatment for fetal growth retardation? Fetal Diag Ther 20: 208-213.

44. Han B, Xu M (2017) A comprehensive analysis of continuous epidural analgesia's effect on labor and neonates in maternal hypertensive disorder patients. Pregnancy Hypertens 7: 33-38. 